\title{
There is no place for the psychoanalytic case report in the British Journal of Psychiatry
}

\author{
Lewis Wolpert/Peter Fonagy
}

\section{Summary}

As evidence-based mental health and the randomised controlled trial come to dominate the content of major psychiatric journals, the status and clinical utility of single case reports have been increasingly questioned. Arguably, owing to their subjective, anecdotal nature and unsuitability for rigorous scientific testing, this is particularly true of psychoanalytic case studies. Professor Peter Fonagy and
Professor Lewis Wolpert debate here whether or not there is a place for such case reports in the British Journal of Psychiatry.

\section{Declaration of interest}

L.W.: none / P.F.: none.

\section{For}

The main problem with psychoanalysis is that it makes no attempt to be based on science and so there are no general principles which a case history could use to help other patients. An analytic case history is essentially subjective and anecdotal, and it also ignores other approaches to mental illnesses. No analyst is likely to consider the possibility that the patients' condition may be due to a genetic defect or some other physical illness. For example, there is good evidence that depression has a strong genetic component and so does schizophrenia. It is unlikely that psychoanalysts would even recognise such diagnoses of the patient's condition. In addition, there is the problem that there are almost as many ideas about psychoanalysis as there are analysts. There is no one accepted theory. For example, Melanie Klein's hypotheses regarding internalisations during the first year of life leading to paranoid and depressive states is without evidence but is not generally accepted.

One analyst has recently examined views of analysts in the USA $^{1}$ and concluded that his study:

reveals a plethora of newer ideas, some areas of consensus, and broad areas of disagreement concerning the meaning and value of the ideas that dominate our current discourse. While we welcome the "pluralism" that has partially replaced the "rejectionist" policy of only a few decades ago, our contemporary pluralism is, to a surprising degree, a multiplicity of authoritarian orthodoxies, each derived from a particular thinker, rather than a scientific discourse.

Modern psychoanalytic interventions are primarily intended to provide a special communication with the patient based on emotion, rather than to promote intellectual insight. Nevertheless, most psychoanalysts continue to stress the strong influence of unconscious elements affecting people's mental lives. There are no accepted diagnoses as in DSM-IV. In psychoanalytic thinking the patient is not suffering from a defined illness and so there is no attempt to find a cure. The technique is not laid down and each analyst will pursue their own approach to interpreting the patient's free associations. There is thus nothing useful to be learned from a case report on an individual that could help other patients. Each case is essentially the relationship between an analyst and a patient.

The relationship between the patient and an analyst is different from that with a psychiatrist, is very personal and not easily expressed or explained. It is claimed that the analyst takes in much of what oozes out of the patient in different non-verbal forms. The patient and analyst enter into a complex relationship. Freud wanted the case histories he wrote to have the stamp of science. On that score he believed he had failed, as an analysis involves what cannot be replicated, like free association. It only happens once. By contrast, the development of an embryo also only happens once, but scientific theory explains how it happens.

Evidence is not something which analysts have much respect for. Almost all ideas in psychoanalysis are not supported by reliable evidence. That we have in our minds an ego, superego and an id is without foundation. Then there are all the claims about dreams providing important information on the patient's thoughts, particularly their unconscious thoughts, for which evidence is again just not there. There is excessive emphasis on the influence of childhood, although many adults with symptom neuroses and character pathology have no history of childhood sexual or physical abuse. And where is the evidence for the Oedipus complex?

One of the problems with psychoanalysis is that it is difficult to be wrong as anything can be explained; there is no evidence with which it assesses any idea or claim. Every explanation seems possible, and this must make it very attractive to those who practise it - how nice to have virtually no constraints. Consider these typical views expressed by the analyst Adam Phillips: ${ }^{2}$

Psychoanalysis does not cure people but shows them what is incurable; the understanding of psychoanalysis involves a continual resistance to it; what happens in therapy has more to do with the therapist's past than the patients; brief therapy is no worse or better: what could be more mine and not mine than my own desire.

So how does one evaluate the technique and its ideas? Case histories would be of no value. In an analytic case study by Marco Chiesa ${ }^{3}$ we merely have a long history of the patient over several years. The analyst was very weary at times and the report does not even reach a conclusion.

By contrast, a good example of a case history published in this journal involved an unusual combination of three problems depression, mild cognitive impairment and sleep disorder. ${ }^{4}$ It was only after detailed questioning that the sleep laboratory confirmed rapid eye movement sleep behaviour disorder, which responded positively to a combination of drugs with nasal continuous positive airways pressure. Drugs do not enter into analytic-based treatments. Another example is the case of an intellectual disability due to a genetic defect on the X-chromosome. ${ }^{5}$ Genes rarely enter into analytic thinking.

It is the insistence of analysts to live in a world of their own that makes it totally unsatisfactory for them to present a clinical case in this journal.

Lewis Wolpert 


\section{Against}

My debate with Professor Wolpert concerning psychoanalysis has a distinguished history. ${ }^{6}$ I will briefly respond to the issues raised, some of which I wholeheartedly agree with. Others are less wellinformed and I am glad to have the opportunity to set the record straight.

First, Professor Wolpert describes psychoanalysis in a way that not everyone would recognise. For example, psychoanalysis does take genetics seriously, starting with Freud (e.g. Freud, ${ }^{7}$ p. 239), but also some classical and more recent psychoanalysts who originated twin and adoption studies ${ }^{8,9}$ or indeed my own inadequate musings. ${ }^{10}$ In fact, the point to be made, particularly in the light of recent evidence on gene-environment interaction, is not related to the futile debate about nurture $v$. nature but rather a far more interesting discourse concerning the role of human subjectivity in filtering environmental experience which might determine the emergence of phenotype from genotype. The key role for psychoanalysis is informing us about the psychological processes that could moderate the expression of particular genes, for example through influencing parental reactions to young children or through partner choice. ${ }^{11,12}$

Is it true that psychoanalysts are not interested in diagnoses? It is undoubtedly accurate that psychoanalysts are deeply dissatisfied with current psychiatric nosology, which they see as being heavily promoted by the pharmacological industry and as being unhelpful clinically and poorly supported empirically. ${ }^{13-15}$ Professor Wolpert singled out depression as a particularly helpful categorisation, yet the National Institute for Health and Clinical Excellence guidelines identified major problems and considerable room for further research in the face of the heterogeneity of treatment responses to be found. ${ }^{16}$ Nor have analysts simply been carping about this; they have produced an 850 -page volume ${ }^{17}$ representing the collaborative efforts of five major psychoanalytic organisations, as well as the Operationalised Psychodynamic Diagnostic system. ${ }^{18}$ My intention here is not to promote these particular volumes but just to challenge Professor Wolpert's assertion that psychoanalysts are uninterested in issues of classification.

I also disagree with the claim that psychoanalysts have no respect for evidence. We may wish to enter an argument about what we mean by evidence, but I would make the strong claim that a group of psychoanalysts have for many decades been fully committed to testing psychoanalytic propositions, both in relation to models of the mind ${ }^{19}$ and in relation to treatment efficacy. ${ }^{20}$ In fact, as it happens, two of the individuals chosen by Professor Wolpert as exemplars of the psychoanalytic community's disregard for evidence, Arnold Cooper and Marco Chiesa, would both consider themselves in this group. Chiesa has undertaken a productive programme of research explicitly demonstrating the limitations of therapeutic communities ${ }^{21-23}$ and Cooper has contributed to numerous empirical research programmes at Cornell Medical College, including the manualisation of a psychodynamic treatment of anxiety disorder. ${ }^{24}$

I would like to formally invite Professor Wolpert to join the psychodynamic researchers' LISTSERV (psychodynamicresearch@ yahoogroups.com), where more than 300 participants actively engaged in accumulating evidence pertinent to psychoanalysis, including biological, psychosocial and clinical research, share their reports, their findings and work in progress. No clinical discipline, to my knowledge, incorporates all its practitioners in research. Similarly in psychoanalysis, it is a relatively small cadre that carry out original research, but the clinical professionals' support for this work is far more tangible than may be the case in other disciplines such as general psychiatry. For example, the International Psychoanalytic Association has spent $\$ 3$ million of its membership dues in recent years supporting a variety of psychoanalytic research projects. The German Psychoanalytic Association has funded a highly successful follow-up study and is currently supporting a prospective comparison study of psychoanalytic psychotherapy and cognitive-behavioural therapy (CBT). ${ }^{25}$ The members voluntarily contribute to these projects because, as we all know, it is extremely difficult to obtain statutory funding for psychoanalytic research. This may be largely a result of the pervasiveness of misconceptions about the unscientific nature of modern psychoanalysis.

Finally, on the issue of pluralism raised by Arnold Cooper's statement, I would agree that there is no single psychoanalytic perspective that has general acceptance within the field. I would maintain that this does not set psychoanalysis apart from other specialist fields of psychotherapy or even mature sciences such as physics or evolutionary biology. But as with these mature fields, to which psychoanalysis cannot yet hope to aspire, there are core constructs that are generally implicitly accepted and well evidenced by both clinical observation and empirical data. In fact, over the past three decades there has been a convergence of assumptions both across psychoanalytic groups and, even more impressively, across different psychotherapeutic specialisations, systemic, cognitive-behavioural, humanistic-experiential and psychoanalytic-psychodynamic. Most psychoanalysts now, as Freud had been towards the end of his career, are humbled by the enormous influence of genetic predisposition modulated by increasing understanding of developmental concepts such as resilience but are also excited by new data on the importance of childhood experience in brain development. Most psychoanalysts recognise that only through a thoroughgoing commitment to understanding 'disease mechanisms' will treatment approaches become optimal in alleviating the suffering associated with mental ill health. Psychoanalysis is the most comprehensive body of knowledge in relation to the complexity of human subjectivity. When its findings are made accessible through the stories of psychoanalysts' encounters with their patients, given judicious critical peer review, they can contribute significantly to this essential understanding.

Peter Fonagy

\section{For: rebuttal}

Professor Fonagy does not deal with the key issue in our debate, namely whether the Journal should publish psychoanalytic case histories as they are not evidence based. In my view, as I argued, they should not be published here because psychoanalysis is not a science. If I were analytically oriented maybe I would interpret his omission in terms of unconscious denial and fear of not having persuasive arguments, or perhaps of a heavy case falling on his toe when young?

Just consider what he has written. ${ }^{20}$

Perhaps the most significant challenge facing those who would like to provide a manual of psychoanalytic technique is the loose relationship between psychoanalytic theory and clinical practice. It is impossible to achieve a one-to-one mapping between psychoanalytic therapeutic technique and any major theoretical framework. Theory and practice have progressed at very different rates - practice has changed in only minor ways relative to the major strides made by theories. Moreover, psychoanalytic theory is largely not about clinical practice. Even when psychoanalysts are working within the same theoretical framework, they find great difficulty in arriving at consensus as to the presence or absence of a psychoanalytic process.

This supports my objection that psychoanalysis is not a science, and so each case history would just be anecdotal, and every one would be different and no general principles would emerge. Each case history would just be a story about the relationship between 
the analyst and the patient. They would also ignore the biological basis of the problem which is so important in many cases.

Looking up the very few psychoanalytic case histories I could find, almost all were for children and they confirmed my views. The case described by Pretorius ${ }^{26}$ is little more than a story of the analyst's relationship with the boy. There does not seem to be any real theory. There is no evidence for his conclusion that the paper explores the different ways in which chronic trauma and the salient traumatic event, experienced in infancy, are repeated, recalled, and expressed verbally and through behaviour. In another case history, Yardino ${ }^{27}$ comments, 'I think the childhood memory and his associations indicate a very relevant moment of this analysis, difficult and fertile, in which the experiences of the analyst and the patient become entwined in the field of experiences.' The analyst is much too involved for there to be a scientific approach.

Compare these with traditional psychiatric case histories. Robertshaw \& MacPherson ${ }^{5}$ show that a young man's intellectual disabilities are due to a genetic error in his X-chromosome. They argue that clinicians should have a high index of suspicion regarding a genetic disorder when meeting someone with a mild intellectual disability.

Another case involved a 74-year-old man with a 4-year history of low mood with increasing irritability and anhedonia associated with apathy, withdrawal from social activities and reduced daytime physical activity. ${ }^{4}$ The onset of affective symptoms was precipitated by moving family home, and exacerbated by the subsequent divorce of his daughter. It was necessary to use a variety of techniques, which included brain computed tomography, magnetic resonance imaging, positron emission tomography, neuropsychological testing and nocturnal polysomnography, and detailed questioning. This led to recognising sleep behaviour disorder, which responded to drugs. Later, when sleep apnoea had been identified in addition, a combination of these drugs with nasal continuous positive airways pressure proved effective.

Turning to depression, the evidence that analysis is a good treatment is weak. Also, analysts would ignore the biological basis of some depressions such as the absence of light in winter, or that alpha-interferon causes depression, so patients treated with it for hepatitis must take antidepressants. There is also the problem with depression that analysis will probably present the patient with more negative events in their lives, which will make the depression worse.

Lewis Wolpert

\section{Against: rebuttal}

In my last response I attempted to reply to Professor Wolpert's comments addressing the scientific status of psychoanalysis. So while I am open to his reconstruction of traumatic childhood toe injury, a more parsimonious account may be found in my evenly hovering attention to his discourse.

Professor Wolpert generously cites my comments on the relationship of theory and practice in psychoanalysis (even more torturously explored elsewhere; see Fonagy ${ }^{28}$ ) and suggests that this loosely coupled relationship is a fatal objection to the use of psychoanalytic case histories. I would claim that psychoanalysis is not alone in finding the linking of theory and practice problematic at times, and in fact the series of articles exploring theory-practice relationships in the special issue of the Journal of Child Clinical Psychology to which my own contribution belongs ${ }^{29}$ underscores this in relation to behaviour therapy, CBT and other popular modes of clinical practice.
So while I would not wish to give ground in relation to Professor Wolpert's objection to the scientific status of my chosen discipline, I will concede readily and enthusiastically that much current practice in reporting cases is deeply flawed, epistemologically as well as heuristically. I even agree with some of his objections, although not all. Professor Wolpert mentions two examples where, in his view, inferences made by the author are unsupported and potentially unsupportable by the clinical observation. I concede that there is a lack of rigour in the reporting of psychoanalytic case histories. Freud's conviction that what ultimately benefits the patient is the discovery of the truth led him to place perhaps undue emphasis on clinical data, permitting them to bear the dual epistemic burden of confirming (a) the analyst's understanding of the patient and (b) general psychoanalytic hypotheses concerning the nature of human development, psychological abnormality and the existence and characteristics of numerous psychic mechanisms. Grünbaum ${ }^{30}$ examined this argument in detail and found it crucially flawed.

Simply stated, the problem is that by and large clinicians are epistemically dependent on their patients' responses to interpretations, even if their criteria for confirmation are more sophisticated than a simple reliance on symptomatic improvement (see Freud, ${ }^{31}$ p. 263). Elsewhere I have suggested that the permissive nature of such strategies has resulted in an accumulation of successful case reports that appear to support an array of psychoanalytic propositions as well as diverse therapeutic methods (e.g. Fonagy \& Target $^{32}$ ). Case reports that were the hallmark of 19 th-century clinical medicine, that used clinical observation and phenomenology as primary research tools, are simply incompatible with therapeutic approaches that arose out of 20th-century social science where the unequivocal establishment of causal connections between intervention and outcome came to be the primary criterion for evidence as embodied within randomised controlled trial (RCT) methodology or, at the level of the individual, experimental single-case studies. ${ }^{33}$

There have been attempts at making clinical reports of the psychotherapeutic process more rigorous. Klumpner \& Frank, ${ }^{34}$ for example, proposed a format for case reports that was somewhat more rigorous than the traditional psychoanalytic format and forced the author to make the logic of inference explicit. I do not believe that this has been taken up by the field to any great extent, and in my view it would be foolhardy to do so. Nothing short of a videotaped or at least tape-recorded analytic encounter could serve as appropriate basis for systematic study and even in that context I believe that the investigator should be someone other than the clinician in charge of the treatment. This kind of psychoanalytic case study has been productively used to help understand the psychotherapeutic process and we have learned important lessons. For example, it has been shown that effective interpretation to patients with borderline personality disorder depends on the prior establishment of a sound therapeutic alliance. ${ }^{35}$

However, does this mean that there should be no space for even the traditional psychoanalytic case report in the pages of a scientific journal such as this one? I would argue that such reports should not be excluded. I would like Professor Wolpert to address an issue that in my view goes beyond the scientific credibility of psychoanalytic ideas, the latter issue being orthogonal to the status of case reports. The interpersonal process that exists between two human beings, the psychiatrist and the patient, is maintained in part by the scientific understandings and intuitions of the clinician, brought to bear on the individual case. But this is not the whole story. We know from large-scale studies such as the National Institute of Mental Health depression trial ${ }^{36}$ that even placebo can be effectively or ineffectively administered. ${ }^{37}$ In the 
NIMH trial, the clinician who was found to be most effective was better at bringing about relief from depression in her patients when administering placebo than the worst therapist was when administering imipramine. There is controversy concerning the variability attributable to the therapist in psychotherapy trials but the balance of expert opinion favours the view that a significant proportion of the variance belongs with the individual practitioner and the practitioner-patient pair, and is not readily reducible to demographic or personality features. ${ }^{38}$

Narrative descriptions of the clinical encounter can, I believe, convey aspects of the therapeutic interaction that are currently beyond the readily quantifiable but nevertheless represent an essential component of the art of psychotherapy. A surgeon's technique will determine the rate of complications and the contribution of the clinician is now recognised by the revised CONSORT guidelines ${ }^{39}$ as an essential source of variance that must be declared in RCTs. Beyond familiarity with the broad outlines of a treatment package as described and assessed in reports of RCTs, the how of psychological therapy also needs to be taught and this may be most effectively conveyed by treatment process reports even if these are idealised representations of the therapeutic encounter.

Peter Fonagy

\section{For: Conclusions}

We have so far not mentioned cognitive therapy, which differs significantly from psychoanalysis. It deals with the patient's conscious thoughts and beliefs, particularly their negative ones, and tries to alter these where appropriate. An aim of the therapy is to alter the patients' behaviour and they are asked to keep a diary. This can be very helpful as the patient may believe that there will never be any improvement but they can see from their diary that there are some good days. A number of case studies using CBT have been published. A nice example is the treatment of patients with Parkinson's disease and depression. ${ }^{40}$

The treatment involved training in stress management, behavioural modification, sleep hygiene, relaxation techniques, and cognitive restructuring. Treatment began by identifying life stressors that appeared to be contributing to depressed mood .

We established a focus on meaningful activities early in treatment in order to help patients maintain and/or achieve a sense of purpose and fulfilment in their lives, despite the progressive nature of Parkinson's disease. Patients were also encouraged to adjust their expectations of themselves, expanding the repertoire of activities that they found to be enjoyable and "do-able", in order to maximise the amount of positive reinforcement derived from the environment. Pleasant activities were also hypothesised to decrease the patients' focus on their physical condition. Because all patients had sleep difficulties, we introduced sleep hygiene techniques, such as avoiding daytime naps and establishing bedtime and wake-up routines. Overall, behavioural strategies were intended to help patients maximise control in their lives.

One can see how a case report on CBT makes sense. More detailed information is contained in Blackburn \& Davidson, ${ }^{41}$ which provides examples of the dialogue between therapist and patient. But it is not just the dialogue that matters but what the patient does to alter their thinking and behaviour.

I recognise how careful one has to be in determining the effectiveness of any therapy for mental illness as the placebo can play a key role, but with psychoanalysis I remain unconvinced that case reports will be of any help, and so the Journal should not publish them.

Lewis Wolpert

\section{Against: Conclusions}

I accept that current psychoanalytic case studies are often not consistent with the minimal standards of reliable reporting that the Journal has the right to expect. Special pleading for a unique epistemology for psychoanalysis ${ }^{25,42}$ is no more justified than it would be for any other subdiscipline of the mental health sciences.

However, I would wish to assert that there is nothing inherently unscientific about the psychoanalytic clinical situation. Its intensity and particular interpersonal resonances continue to offer unique insights vital for the understanding of the human social condition. It enables us to question that which we normally overlook. As Jonathan Lear put it: 'psychoanalysis begins in wonder that the unintelligibility of the events which surround one do not cause more wonder' (see Lear, ${ }^{43}$ p. 28 ). We remain blind to the proliferation of meanings for which human subjectivity is responsible but which escapes it - 'knowingness', as Lear terms it. This is a cultural condition as well as an individual state of mind. The commitment of psychoanalysis to this pursuit becomes vital to the human enterprise when confronting massive social problems that hide behind the ordinary, Hannah Arendt's 'banality of evil' that is not executed by fanatics or sociopaths but rather by ordinary people who accept the premises of their social context and therefore participate with the view that their actions are normal. Moreover, how else can one come to understand the motivation of child abusers, war criminals, terrorists and murderers? These are aspects of human behaviour that have to be studied in depth and in a 'no holds barred' exploration of personal meanings. Equally, on a more positive note, the psychoanalytic clinical situation can illuminate how people survive adversity. More generally, wherever a question is socially important and where we need reflection to check out how well our reasoning is going, case reports of intensive psychotherapy can provide important understandings about the thoughts, wishes, and beliefs and desires characterising such unusual individuals, and can provide a fertile source of hypotheses about psychological causes of destructive or constructive action.

Obviously, case studies will be more interesting if placed in the context of other independent measures. Developmental psychopathology has made us aware that brain development affects behaviour but experience also affects brain development. ${ }^{44}$ For example, we know that in some of those who have suffered emotional abuse, cerebral spinal fluid oxytocin levels appear to be low. ${ }^{45}$ Would it not be fascinating to know how the proliferation of meanings in the minds of these individuals differs from those whose oxytocin was not affected in this way? Such examples provide a clue about the minimal criteria for admitting a psychoanalytic case study into the Journal. These criteria should include:

(a) the case study should be hypothesis-driven (i.e. start with a research question before the patient was seen);

(b) the reporting and recording methods of the process should meet with minimal standards of replicability;

(c) the reporting should be transparent and open to public scrutiny, including perhaps the provision of full case reports as supplementary materials;

(d) assurance should be available that the patient has offered informed consent both to the recording and to the report;

(e) an acceptable supplementary methodology of either a quantitative or a qualitative type should be used to ensure the triangulation of findings.

Psychoanalysis has survived as a psychology in the evolutionary battle of ideas because it has made unique contributions, sharpening our vision of man throughout the 20th century. This learning was based on clinical enquiry with all the limitations that Professor Wolpert has pointed to. I wish to strongly advocate that the meticulous study of human subjectivity offered by the intersubjective experience of psychotherapy be combined with novel 
methods of neuroscience and molecular genetics as well as the established methods of systematic social science research in order to take us to a new era of discovery based in clinical work.

Peter Fonagy

For: Lewis Wolpert, FRS, Emeritus Professor of Biology as Applied to Medicine, Department of Cell and Developmental Biology, University College London, Gower Street, London WC1E 6BT, UK. Email: I.wolpert@ucl.ac.uk

Against: Peter Fonagy, PhD, FBA, Freud Memorial Professor of Psychoanalysis and Head of the Research Department of Clinical, Educational and Health Psychology, University College London, Gower Street London WC1E 6BT, UK. Email: p.fonagy@ucl.ac.uk

\section{References}

1 Cooper AM. American psychoanalysis today: a plurality of orthodoxies. Am Acad Psychoanal Dyn Psychiatry 2008; 36: 235-53.

2 Phillips A. Side Effects. Penguin, 2007.

3 Chiesa M. Pathological organisations of the personality: a clinical case study. Br J Psychother 2007; 23: 395-410.

4 Clarke NA, Williams AJ, Kopelman MD. Rapid eye movement sleep behaviou disorder, depression and cognitive impairment. Case study. Br J Psychiatry 2000; 176: 189-92.

5 Robertshaw BA, MacPherson J. Scope for more genetic testing in learning disability. Case report of an inherited duplication on the X-chromosome. Br J Psychiatry 2006; 189: 99-101.

6 Fonagy P, Wolpert L. Has Freudian psychoanalysis been killed by pills? [Debate]. Prospect 1999; November: 16-20.

7 Freud S. Three essays on the theory of sexuality. In The Standard Edition of the Complete Psychological Works of Sigmund Freud (volume 7) (ed J Strachey): 123-230. Hogarth Press, 1937.

8 Haddad SK, Reiss D, Spotts EL, Ganiban J, Lichtenstein P, Neiderhiser JM. Depression and internally directed aggression: genetic and environmental contributions. J Am Psychoanal Assoc 2008; 56: 515-50.

9 Neubauer PB. Nature's Thumbprint: The New Genetics of Personality (2nd edn). Columbia University Press, 1996.

10 Fonagy $P$. The development of psychopathology from infancy to adulthood: the mysterious unfolding of disturbance in time. Infant Ment Health J 2003; 24: 212-39.

11 Reiss D, Cederblad M, Pedersen NL, Lichtenstein P, Ethammar O, Neiderhiser JM, et al. Genetic probes of three theories of maternal adjustment: II. Genetic and environmental influences. Fam Process 2007; 40: $261-72$.

12 Reiss D, Leve L. Genetic expression outside the skin: clues to mechanisms of Genotype Environment interaction. Dev Psychopathol 2007; 19: 1005-27.

13 Luyten P, Blatt SJ. Looking back towards the future: is it time to change the DSM approach to psychiatric disorders? The case of depression. Psychiatry 2007; 70: 85-99.

14 Russ E, Shedler J, Bradley R, Westen D. Refining the construct of narcissistic personality disorder: diagnostic criteria and subtypes. Am J Psychiatry 2008 165: $1473-81$.

15 Westen D, Shedler J. Personality diagnosis with the Shedler-Westen Assessment Procedure (SWAP): integrating clinical and statistical measurement and prediction. J Abnorm Psychol 2007; 116: 810-22.

16 National Institute for Health and Clinical Excellence. Depression: Management of Depression in Primary and Secondary Care. NICE, 2004.

17 Alliance of Psychoanalytic Organizations. Psychodynamic Diagnostic Manual (PDM). Interdisciplinary Council on Developmental \& Learning Disorders, 2006.

18 Arbeitkreis OPD (ed). Operationalisierte Psychodynamische Diagnostik: Grundlagen und Manual. Hans Huber, 1996.

19 Luyten P, Blatt SJ, Corveleyn J. Minding the gap between positivism and hermeneutics in psychoanalytic research. J Am Psychoanal Assoc 2006; 54: 571-610.

20 Gabbard GO, Gunderson JG, Fonagy P. The place of psychoanalytic treatments within psychiatry. Arch Gen Psychiatry 2002; 59: 505-10.
21 Chiesa M, Fonagy P. Psychosocial treatment for severe personality disorder. 36-month follow-up. Br J Psychiatry 2003; 183: 356-62.

22 Chiesa M, Fonagy $\mathrm{P}$, Holmes J. Six-year follow-up of three treatment programs to personality disorder. J Personal Disord 2006; 20: 493-509.

23 Chiesa M, Fonagy P, Holmes J, Drahorad C. Residential versus community treatment of personality disorders: a comparative study of three treatment programs. Am J Psychiatry 2003; 161: 1463-70.

24 Milrod B, Busch F, Cooper A, Shapiro T. Manual of Panic-Focused Psychodynamic Psychotherapy. American Psychiatric Publishing, 1997.

25 Leuzinger-Bohleber M, Target M (eds). The Outcomes of Psychoanalytic Treatment. Whurr, 2002.

26 Pretorius IM. Repeating and recalling preverbal memories through play: the psychoanalysis of a six-year-old boy who suffered trauma as an infant Psychoanal Study Child 2007; 62: 239-62.

27 Yardino SM. 'Break point': a significant moment in the transference. Int J Psychoanal 2008; 89: 241-7.

28 Fonagy $\mathrm{P}$. Some complexities in the relationship of psychoanalytic theory to technique. Psychoanal $Q$ 2003; 72: 13-47.

29 Fonagy $\mathrm{P}$. The relation of theory and practice in psychodynamic therapy. J Clin Child Psychol 1999; 28: 513-20.

30 Grünbaum A. The Foundations of Psychoanalysis: A Philosophical Critique. University of California Press, 1984.

31 Freud S. Analysis terminable and interminable. In The Standard Edition of the Complete Psychological Works of Sigmund Freud (volume 23) (ed J Strachey): 209-53. Hogarth Press, 1937.

32 Fonagy P, Target M. Psychoanalytic Theories: Perspectives from Developmental Psychopathology. Whurr, 2003.

33 Fonagy P, Moran G.S. Selecting single case research designs for clinicians. In Psychodynamic Treatment Research: A Handbook for Clinical Practice (eds NE Miller, L Luborsky, JP Barber et al): 62-95. Basic Books, 1993.

34 Klumpner $\mathrm{GH}$, Frank A. On methods of reporting clinical material. J Am Psychoanal Assoc 1991; 39: 537-52.

35 Horwitz L, Gabbard GO, Allen JG, Frieswyk SH, Colson DB, Newsom GE, et al. Borderline Personality Disorder: Tailoring the Psychotherapy to the Patient. American Psychiatric Press, 1996.

36 Elkin I, Shea MT, Watkins JT, Imber SD, Sotsky SM, Collins JF, et al. National Institute of Mental Health Treatment of Depression Collaborative Research Program. General effectiveness of treatment. Arch Gen Psychiatry 1989; 46: 971-82.

37 Blatt SJ, Sanislow CA, Zuroff DC, Pilkonis PA. Characteristics of effective therapists: further analyses of data from the National Institute of Mental Health Treatment of Depression Collaborative Research Program. J Consult Clin Psychol 1996; 64: 1276-84.

38 Beutler L, Malik M, Alimohamed S, Harwood M, Talchi H, Noble S, et al. Therapist variables. In Bergin and Garfield's Handbook of Psychotherapy and Behavior Change (ed M Lambert): 227-306. Wiley, 2004.

39 Moher D, Schulz KF, Altman DG. The CONSORT statement: revised recommendations for improving the quality of reports of parallel-group randomised trials. Lancet 2001; 357: 1191-4.

40 Dobkin RD, Allen LD, Menza M. A cognitive-behavioral treatment package for depression in Parkinson's disease. Psychosomatics 2006; 47: 259-63.

41 Blackburn IM, Davidson K. Cognitive Therapy for Depression and Anxiety. Blackwell, 1995.

42 Hampe M. Pluralismus der Wissenschaften und die Einheit der Vernunft. In Die Erfahrungen, die wir machen, widersprechen den Erfahrungen, die wir haben. Formen der Erfahrung in den Wissenschaften (ed M Hampe). Duncker und Humblot, 2000.

43 Lear J. Open Minded: Working Out the Logic of the Soul. Harvard University Press, 1998.

44 Cicchetti D, Valentino K. An ecological-transactional perspective on child maltreatment: failure of the average expectable environment and its influence on child development. In Developmental Psychopathology, Volume 3 (2nd edn) (eds D Cicchetti, DJ Cohen): 129-201. John Wiley \& Sons, 2006

45 Heim C, Young $\amalg$, Newport DJ, Mletzko T, Miller AH, Nemeroff CB. Lower CSF oxytocin concentrations in women with a history of childhood abuse. Mol Psychiatry 2008; Epub ahead of print. 